\title{
Assembly of Two New Coordination Polymers: Luminescent Properties and Anti-inflammatory Activity on Postoperative Infectious Endophthalmitis
}

\section{Guang-Qing Bian ( $\sim$ bianguangqing@163.com )}

Department of Ophthalmology, The First Affiliated Hospital of Shandong First Medical University \& Shandong Provincial Qianfoshan Hospital, Jinan, Shandong, China

\section{Shi-Xi Zhang}

Department of Ophthalmology, Aier Eye Hospital of Dezhou, Dezhou, Shandong, China

Xiao-Li Qu

Department of Ophthalmology, The First Affiliated Hospital of Shandong First Medical University \& Shandong Provincial Qianfoshan Hospital, Jinan, Shandong, China

\section{Research Article}

Keywords: Solvothermal synthesis, Interpenetrated framework, Luminescence, PIE, biological evaluation

Posted Date: June 22nd, 2021

DOl: https://doi.org/10.21203/rs.3.rs-635113/v1

License: (c) (1) This work is licensed under a Creative Commons Attribution 4.0 International License. Read Full License 


\section{Abstract}

The solvothermal reactions via the self-assemble approach produced two new metal-organic compounds, i.e, $\left[\mathrm{Zn}(4-\mathrm{cptpy})(\mathrm{HCOO})\left(\mathrm{H}_{2} \mathrm{O}\right)\right]_{\mathrm{n}} \cdot \mathrm{n}(\mathrm{DMF})(\mathbf{1})$ and $\left[\mathrm{Cd}_{3}(\mathrm{btc})_{2}(4-\mathrm{cptpyH})(\mathrm{DMF})\left(\mathrm{H}_{2} \mathrm{O}\right)_{3}\right]_{\mathrm{n}}(2)(\mathrm{DMF}$ is N,N'dimethylformamide, $\mathrm{H}_{3}$ btc is benzene-1,3,5-tricarboxylic acid, and 4-Hcptpy is 4-[2,6-bis(pyridine-4yl)pyridine-4-yl]benzoic acid). Furthermore, the compounds' luminescent performances have also been studied. As a result, compounds 1-2 show intense luminescence at room temperature. The evaluation of their application values against postoperative infectious endophthalmitis (PIE) was implemented and their specific mechanism was investigated. First of all, the real time reverse transcription-polymerase chain reaction (RT-PCR) was performed and the nuclear factor kappa-B (NF-kb) signaling pathway activation levels were measured. In addition to this, the inflammatory cytokines content released after the cataract surgery was determined through exploiting the enzyme linked immunosorbent assay (ELISA) detection kit.

\section{Introduction}

Postoperative infectious endophthalmitis (PIE) still cannot be completely avoided. The disease seriously affects vision, with poor recovery. There is still a big gap in the medical level of hospitals at all different levels in our country [1]. The incidence of PIE in large-scale ophthalmic institutions in my country is $0.033 \%$, while the incidence of a PIE in small and medium-sized ophthalmology patients is as high as $0.11 \%$, which is 3 times of the incidence of large-scale ophthalmic institutions [2]. The level of prevention and treatment of endophthalmitis after cataract extraction in our country needs to be further improved.

Postoperative infectious endophthalmitis (PIE) is caused by infection and inflammation of intraocular tissues due to the invasion of pathogens. The common causes are: corneal penetrating injury, intraocular extraneous matter, intraocular surgery. Incision infection after surgery is one of the most serious complications of shell surgery, which prolongs the patient's hospital stay and causes great harm to the patient's body and mind. During the procession of the PIE, there was usually combined with an increased level of inflammatory cytokines in the corneal endothelial cells, reflected as the activation of NF-KB signaling pathway. Thus, new candidates targeting the NF-KB signaling pathway were needed to be developed.

During the past few decades, as a kind of hybrid materials, the metal-organic frameworks (MOFs) have obtained wide exploration interest because of their extensive applications prospects in the heterogeneous catalysis, luminescence, nonlinear optics, gas storage/separation areas [3-6]. Up to now, various synthetic strategies have been developed to fabricate crystalline MOFs, e.g., mixed-ligand method, template-directed synthesis, pillar-layered strategy, second building unit method [7-10]. However, the structures of MOFs are sensitive to various reaction conditions, including reaction temperature, reaction solvent, $\mathrm{pH}$ value, auxiliary ligand, reactant stoichiometry, template agent, the functionality of the organic ligands, and so on [11-15]. Each change of the above factors may result in significant changes in the topology and structure. An important challenge therefore is to rationally achieve the preferred structures 
with specific properties at molecular level. For the purpose of this, it is crucial to intelligently select suitable organic ligands with appropriate functional groups and geometries. To the best of our knowledge, the selected organic ligands possess a critical effect in construction and determination of functional properties and structure of the MOFs [16]. In addition to this, MOFs also proved having the excellent application values on the anti-inflammatory disease, thus, its treatment on the PIE disease was evaluated in this present research.

In contrast to the widely used bridging carboxylic acid ligand, bifunctional pyridine carboxylic acids with large spacers between the coordination groups are still rarely used for the construction of MOFs [17-20]. Therefore, in this work, we selected a polytopic pyridine carboxylic acid ligand, namely 4-[2,6-bis(pyridine4-yl)pyridine-4-yl]benzoic acid (4-Hcptpy) (Scheme 1), which has three pyridine $\mathrm{N}$ donors and one carboxylate group which can be used as desired building blocks to synthesize new MOFs. Via the solvothermal reactions of 4-Hcptpy with Zn(II) ions or $\mathrm{Cd}$ (II) ions and benzene-1,3,5-tricarboxylic acid $\left(\mathrm{H}_{3} \mathrm{btc}\right)$, we successfully obtained two fresh coordination polymers, namely [Zn(4-cptpy)(HCOO) $\left.\left(\mathrm{H}_{2} \mathrm{O}\right)\right]_{n} \cdot n(\mathrm{DMF})(\mathbf{1})$ and $\left[\mathrm{Cd}_{3}(\mathrm{btc})_{2}(4-\mathrm{cptpyH})(\mathrm{DMF})\left(\mathrm{H}_{2} \mathrm{O}\right)_{3}\right]_{\mathrm{n}}(2)\left(\mathrm{DMF}\right.$ is $\mathrm{N}, \mathrm{N}^{\prime}$-dimethylformamide, $\mathrm{H}_{3}$ btc is benzene-1,3,5-tricarboxylic acid, and 4-Hcptpy is 4-[2,6-bis(pyridine-4-yl)pyridine-4-yl]benzoic acid). The created compounds' luminescent performances were also explored at environmental temperature. After serial experiments, the anti-inflammatory activity of the compound on PIE was determined, and the specific mechanism of the new compound was explored as well. Finally, we draw this conclusion, compound 1 reveals much more outstanding application values on PIE than compound 2 through inhibiting the inflammatory response.

\section{Experimental}

\section{Materials and instrumentation}

The raw solvents and the materials employed in our investigation were provided via the Jinan Camolai Trading Company with 98 percent chemical purity. Elemental analyses (EA) of $\mathrm{C}, \mathrm{H}$, and $\mathrm{N}$ analyses were performed on a Perkin-Elmer $240 \mathrm{C}$ elemental analyzer. The PXRD could be analyzed and then the data were measured using the powder diffractometer of PANalytical X'Pert Pro utilizing the $\mathrm{Cu} / \mathrm{Ka}$ radiation (with $\lambda$ of $1.54056 \AA$ ) with $0.05^{\circ}$ step size. For the two compounds, their thermogravimetric analysis were carried out using the thermoanalyzer of NETSCHZ STA-449C under the atmosphere of $\mathrm{N}_{2}$ with $10^{\circ} \mathrm{C} / \mathrm{min}$ rate between 30 and $700^{\circ} \mathrm{C}$. And the compounds' fluorescence spectra data could be harvested with the Edinburgh Analytical instrument FLS920.

\section{Synthesis of [Zn(4-cptpy)(HCOO)( $\left.\left.\mathrm{H}_{2} \mathrm{O}\right)\right]_{n} \cdot \mathrm{n}(\mathrm{DMF})(1)$ and $\left[\mathrm{Cd}_{3}(\mathrm{btc})_{2}(4-\mathrm{cptpyH})(\mathrm{DMF})\left(\mathrm{H}_{2} \mathrm{O}\right)_{3}\right]_{\mathrm{n}}(2)$}

The mixture formed by $\mathrm{Zn}\left(\mathrm{NO}_{3}\right)_{2} \cdot 6 \mathrm{H}_{2} \mathrm{O}(0.05 \mathrm{mmol}$ and $15 \mathrm{mg}), 4$-Hcptpy $(0.1 \mathrm{mmol}, 35 \mathrm{mg}), 2 \mathrm{~mL}$ of DMF and $1 \mathrm{~mL}$ of $\mathrm{H}_{2} \mathrm{O}$ were kept into a small glass bottle $(10 \mathrm{~mL})$ for 48 hours at $110^{\circ} \mathrm{C}$ and then the 
product was cooled at $2{ }^{\circ} \mathrm{C} / \mathrm{min}$ declining rate to the room temperature. As a result, the 1 's colorless massive crystals could be separated in yield of 38 percent according to the $\mathrm{Zn}\left(\mathrm{NO}_{3}\right)_{2} \cdot 6 \mathrm{H}_{2} \mathrm{O}(0.019 \mathrm{mmol}$, $10.5 \mathrm{mg}$ ). Anal. calcd. for $\mathrm{C}_{26} \mathrm{H}_{24} \mathrm{~N}_{4} \mathrm{O}_{6} \mathrm{Zn}$ (553.86): $\mathrm{N}, 10.11 \%$; C, $56.33 \%$ and $\mathrm{H}, 4.33 \%$. Found: $\mathrm{N}, 10.08 \%$; $\mathrm{C}, 56.28 \%$ and $\mathrm{H}, 4.37 \%$.

The mixture created via $\mathrm{Cd}\left(\mathrm{NO}_{3}\right)_{2} \cdot 4 \mathrm{H}_{2} \mathrm{O}(0.1 \mathrm{mmol}, 30 \mathrm{mg}), \mathrm{H}_{3}$ btc $(0.024 \mathrm{~g}$ and $0.05 \mathrm{mmol}), 4$-Hcptpy $(0.025 \mathrm{mmol}, 9 \mathrm{mg}), 2 \mathrm{~mL}$ of DMF and $1 \mathrm{~mL}$ of $\mathrm{H}_{2} \mathrm{O}$ were maintained into a small glass bottle $(10 \mathrm{~mL})$ for 48 hours at $110^{\circ} \mathrm{C}$ and then the product was cooled at $2{ }^{\circ} \mathrm{C} / \mathrm{min}$ declining rate to room temperature. Finally, the 2's colorless massive crystals could be separated in 28 percent yield on the basis of the $\mathrm{H}_{3}$ btc (0.014 mmol, $17 \mathrm{mg}$ ). Anal. calcd. for $\mathrm{C}_{43} \mathrm{H}_{34} \mathrm{Cd}_{3} \mathrm{~N}_{4} \mathrm{O}_{18}$ (1231.92): $\mathrm{N}, 4.55 \%$; $\mathrm{C}, 41.89 \%$ and $\mathrm{H}, 2.76 \%$. Found: $\mathrm{N}, 4.5 \% 2 ; \mathrm{C}, 41.84 \%$ and $\mathrm{H}, 2.78 \%$.

\section{X-ray crystallography}

The data of two compounds of single crystal has been harvested by the graphite-monochromated MoKa radiation (with $\lambda$ of $0.71073 \AA$ ) via employing the diffractometer of Xcalibur, Eos, Gemini controlled by computer at 293(2) K. Dual direct approach is applied to solve the compounds' architecture utilizing the Shel $X T$, and then SHELXL-2014 is utilized to refine this structure via $F^{2}$ based full-matrix least squares method [21]. SADABS was employed to complete the absorption correction. The compounds' data of crystallography and the optimization of structure were detailed and then calculated in the Table 1 . The chose bond angles $\left(^{\circ}\right)$ and bond lengths $(\AA)$ of the two complexes are revealed in the Table S1. And the specific H-bond parameters for the complex 1 were reflected in the Table S2. 
Table 1

Crystallographic data of compounds 1 and 2.

\begin{tabular}{|lll|}
\hline Sample & $\mathbf{1}$ & $\mathbf{2}$ \\
\hline Formula & $\mathrm{C}_{26} \mathrm{H}_{24} \mathrm{~N}_{4} \mathrm{O}_{6} \mathrm{Zn}$ & $\mathrm{C}_{43} \mathrm{H}_{34} \mathrm{Cd}_{3} \mathrm{~N}_{4} \mathrm{O}_{18}$ \\
\hline FW & 553.86 & 1231.92 \\
\hline Crystal system & monoclinic & monoclinic \\
\hline Space group & $P 2_{1} / \mathrm{c}$ & $C 2 / \mathrm{c}$ \\
\hline$a(\AA)$ & $7.1563(2)$ & $23.3925(3)$ \\
\hline$b(\AA)$ & $26.6425(7)$ & $31.7842(5)$ \\
\hline$c(\AA)$ & $12.9087(4)$ & $16.9235(2)$ \\
\hline$a^{\circ}$ & 90 & 90 \\
\hline$\beta^{\circ}$ & $106.018(4)$ & $128.6460(10)$ \\
\hline$P^{\circ}$ & 90 & 90 \\
\hline Volume $\left(\AA^{3}\right)$ & $2365.64(13)$ & $9827.4(3)$ \\
\hline$Z$ & 4 & 8 \\
\hline Density (calculated) & 1.555 & 1.663 \\
\hline Abs. coeff. (mm $\left.{ }^{-1}\right)$ & 1.887 & 10.953 \\
\hline Total reflections & 7194 & 26821 \\
\hline Unique reflections & 4228 & 10230 \\
\hline Goodness of fit on $F^{2}$ & 1.061 & 2078346 \\
\hline Final $R$ indices $[/>2 s i g m a(R)]$ & $R=0.0363, w R_{2}=0.0998$ & $R=0.0403, w R_{2}=0.1039$ \\
\hline$R($ all data) & $R=0.0387, w R_{2}=0.1018$ & $R=0.0428, w R_{2}=0.1059$ \\
\hline CCDC & 2078345 & \\
\hline & & \\
\hline
\end{tabular}

\section{Real time RT-PCR}

The real time RT-PCR was performed in our research for the assessment of the NF-kb signaling pathway activation levels during the PIE after the treatment of compound. This research was carried out completely based on the instructions' guidance with a little modification. In brief, 40 SD rats used in this study were obtained from Shanghai Southern Model Biotechnology Co., Ltd. (Shanghai, China). Before the experiment, the cells were cultured in a condition of standard laboratory (i.e, the temperature range from $20{ }^{\circ} \mathrm{C}$ to $25^{\circ} \mathrm{C}$ and 45 percent of humidity) with free water and free food. Then, the cataract surgery 
was conducted and the Staphylococcus epidermidis was used to induce the postoperative infection, compounds were given for indicated treatment $(5 \mathrm{mg} / \mathrm{kg})$. After that, the cataract endothelial cells were isolated and in cells, the entire RNA could be extracted via exploiting the TRIZOL regent. After measuring the totsI RNA concentration, and it was subsequently reverse transcripted into the cDNA. Finally, the relative expression levels of the $n f-k b$ and $p 53$ was measured via exploiting the real time RT-PCR, with the gapdh was acted as an internal control gene.

\section{ELISA detection assay}

After the PIE animal construction and compound treatment, the ELISA detection kit was employed for the determination of the inflammatory cytokines content released after cataract surgery. This experiment was finished strictly in accordance with the protocols with only a little change. In short, the cataract surgery was conducted and the Staphylococcus epidermidis was used to induce the postoperative infection, compounds were given for indicated treatment $(5 \mathrm{mg} / \mathrm{kg})$. Subsequently, the plasma was collected and the content of inflammatory cytokines released after cataract surgery was detected.

\section{CCK-8 assay}

To determine the inhibitory effect of the new compound on the viability of corneal endothelial cells, the CCK-8 assay was implemented in this present research. This experiment was conducted totally under the guidance of the instructions with only a little change. In brief, the corneal endothelial cells, in logical growth phage were harvested and then cultured into the 96 well plates at $10^{4}$ cells per well concentration, which was then cultured in an incubator at the condition of $37^{\circ} \mathrm{C}, 5 \% \mathrm{CO}_{2}$. Then, the new compound was added for the treatment with serial different concentrations. Subsequently, the cell culture medium was discarded and then fresh medium containing $10 \mu \mathrm{L}$ the CCK-8 reagent was added with the into cells for the treatment. Ultimately, the absorbance of each well was measured by flow cytometry at $490 \mathrm{~mm}$ at least three times. The results were represented as mean \pm standard deviation.

\section{Results And Discussion}

\section{Crystal structure of compound 1}

The complex 1's crystal structure was characterized through the structural research of X-ray, displaying that the 1 was crystallized in a space group $P Z_{1} / \mathrm{c}$ of monoclinic system which has an asymmetric unit includes a coordinated anion of formate, a ligand of 4-cptpy', a Zn(II) ions, a coordinate molecule of $\mathrm{H}_{2} \mathrm{O}$ along with a lattice molecule of DMF. As reflected in the Fig. 1a, each of the $\mathrm{Zn}$ (II) ions is hexacoordinated, which is occured in the slightly distorted coordination surrounding of octahedron. The equatorial plane of this octahedron is defined via $2 \mathrm{~N}$ atoms (namely, N2b and N3) and 2 carboxylate oxygen atoms ( $01 \mathrm{a}$ and $02 \mathrm{a}$ ) in 3 diverse ligands of 4-cptpy ${ }^{-}$, and apical positions are taken over through 20 donors (i.e, 03 and $01 \mathrm{w}$ ) in a coordinated molecule of water and an anion of formate. The 4-Hcptpy ligand deprotonates into the 4-cptpy ${ }^{-}$ligand, which utilizes as the tridentate ligand and it coordinates with 3 zinc (II) ions through 2 outer pyridyl groups and one chelating carboxylic acid group (Fig. S1a). The 
four aromatic rings of the 4-cptpy ${ }^{-}$ligand in 1 are not coplanar. The bond lengths and bond angle parameters around $\mathrm{Zn}$ (II) are listed in Table S1. All of the $\mathrm{Zn}$ (II) ions are linked through the tridentate ligands of 4-cptpy ${ }^{-}$into a two-dimensional layer containing the large hexagonal windows viewing along crystallographical $a$ axis (Fig. 1b). Owing to the existence of large hexagonal windows in the layer, adjacent 2D are interpenetrated with each other, forming a 2D $+2 D \rightarrow 2 D$ interpenetrated layer motif (Fig. 1C). In this framework, the Zn(II) ions and the tridentate ligands of 4-cptpy ${ }^{-}$were identified as threelinked nodes, hence, the above layer motif can be classified in topology into the three-linked 2-fold interpenetrated net of hcb with $\left\{6^{3}\right\}$ point symbol (Fig. S2) [22]. In the end, the interactions of H-bonding between the $\mathrm{O}$ atoms of the formate anions in neighboring interpenetrating bilayers and coordinated molecules of $\mathrm{H}_{2} \mathrm{O}$ linked these two-dimensional layer motifs to construct a three-dimensional supramolecular skeleton (Fig. 1d). The lattice molecules of DMF are trapped in channels through the $\mathrm{H}$ bonds between the $\mathrm{O}$ atoms and coordinated molecules of the DMF molecules. The parameters of $\mathrm{H}$ bonding are displayed in the Table $\mathrm{S} 2$.

\section{Crystal structure of compound 2}

The structural study of $\mathrm{X}$-ray suggested that the 2 is crystallized in the space group $C 2 / \mathrm{c}$ of monoclinic system and exhibits a 3D skeleton having $(3,6)$-linked topology. And its basic unit is composed of 3 separated $\mathrm{Cd}(\mathrm{II})$ ions, 2 ligands of $\mathrm{btc}^{3-}$, a ligand of 4-cptpyH, a coordinated molecule of DMF and 3 coordinated molecules of water. As displayed in the Fig. 2a, three crystallographically separated $\mathrm{Cd}(\mathrm{II})$ ions are in the 7-coordinated bipyramidal geometry of pentagon. The pentagonal bipyramid for $\mathrm{Cd} 1$ is defined by 5 carboxylic acid 0 atoms in 3 ligands of btc $^{3-}$, a 0 atom from the molecule of DMF, along with a $\mathrm{N}$ atom come from the ligand of 4-cptpyH. For the $\mathrm{Cd} 2$ ion, it surrounded through 5 carboxylic acid $\mathrm{O}$ atoms originate from 3 ligands of $\mathrm{btc}^{3-}$, a $\mathrm{O}$ atom in the coordinated molecule of water, as well as a $\mathrm{N}$ atom derived from the ligand of 4-cptpyH. The $\mathrm{Cd}_{3} \mathrm{O}_{7}$ polyhedron is constituted by 4 carboxylic acid $\mathrm{O}$ atoms in 2 ligands of btc $^{3-}$, a carboxylate $\mathrm{O}$ atom come from a ligand of 4-cptpyH and 2 coordinated molecules of water. The bond lengths of $\mathrm{Cd}-\mathrm{N}$ and $\mathrm{Cd}-\mathrm{O}$ are ranged from 2.288(3) $\AA$ to 2.304(3) $\AA$ and from 2.286(6) $\AA$ to 2.552(3) $\AA$, respectively, they are all in a normal range, according to the reported Cd(II)based polymers [23]. Different from 1, the inner pyridyl group of 4-cptpy ${ }^{-}$ligand is protonated, which also acts as a tridentate ligand linking to $3 \mathrm{Cd}$ (II) ions through 2 outer pyridyl groups and one monodentate carboxyl group (Fig. S1b). Two separated ligands of btc ${ }^{3-}$ in crystallography employ the identical coordination manner: $\left[\mu_{2}-\left(\mu_{2}-\kappa^{1}\right)-\mu_{2}\right]-\mu_{4}$ (Fig. S1c). Cd1 and Cd2 are linked via 2 carboxylic acid groups into the dinuclear subunit of $\left[\mathrm{Cd}_{2}(\mathrm{COO})_{2}\right]$, and the length of $\mathrm{Cd}$...Cd is $3.80 \AA$ (Fig. S3). These dinuclear subunits of $\left[\mathrm{Cd}_{2}(\mathrm{COO})_{2}\right]$ and $\mathrm{Cd} 307$ polyhedrons are connected together via 4-cptpyH and btc ${ }^{3-}$ ligands, extending into the 3D skeleton (Fig. 2b). In the above three-dimensional skeleton, it can be observed that each dinuclear subunit of $\left[\mathrm{Cd}_{2}(\mathrm{COO})_{2}\right]$ is linked with four btc ${ }^{3-}$ ligands and two 4-cptpyH ligands, each 4cptpyH ligand and btc ${ }^{3-}$ ligand connected with 2 dinuclear subunits of $\left[\mathrm{Cd}_{2}(\mathrm{COO})_{2}\right]$ and one $\mathrm{Cd}_{3} \mathrm{O}_{7}$ polyhedron, and each $\mathrm{Cd}_{3} \mathrm{O}_{7}$ polyhedron is surrounded by two btc ${ }^{3-}$ ligands and one 4-cptpyH ligand. 
Topologically speaking, the 4-cptpyH ligands, btc ${ }^{3-}$ ligands, $\mathrm{Cd} 307$ polyhedrons can be considered as three-linked nodes, and the dinuclear subunits of $\left[\mathrm{Cd}_{2}(\mathrm{COO})_{2}\right]$ can be identified as six-linked nodes, as a result, the 2's entire skeleton reflects an unprecedented $(3,6)$-linked network of topology based on four different nodes and the point symbol is $\left\{4 \cdot 6^{2}\right\}_{2}\left\{4^{2} \cdot 6^{4} ; 8^{4} \cdot 10^{5}\right\}\left\{6 \cdot 8^{2}\right\}_{2}$ (Fig. 2c).

\section{Powder X-ray diffraction patterns (PXRD) and thermogravimetric analyses (TGA)}

The two compounds' patterns of PXRD are reflected in the Fig.S4. Significantly, the patterns of experiment are in accordance with the patterns of simulation acquired by the data of single crystal diffraction, revealing the two compounds' as-created samples are pure phase.

Furthermore, the research of TGA were also implemented to assess the compounds' thermal stabilities and the results of TGA are illustrated in Fig. 3 . For 1, the first $16.51 \%$ of weightlessness appeared ranging from 100 to $137{ }^{\circ} \mathrm{C}$, which is due to the loss of the coordinated molecules of DMF and water (with $16.45 \%$ calculated value), and the second weight loss from 300 to $372{ }^{\circ} \mathrm{C}$ was resulted from the organic ligand decomposition. The remaining residues correspond to the generation of $\mathrm{ZnO}$ (obsd: $14.52 \%$, calcd: $14.62 \%)$. For 2 , the first weight loss of $10.22 \%$ from 109 to $148{ }^{\circ} \mathrm{C}$ demonstrated that the coordinated molecules of DMF and water were fully removed (calcd: $10.32 \%$ ), and the second weight loss from 309 to $409{ }^{\circ} \mathrm{C}$ was resulted from the organic ligands decomposition, leaving $31.22 \%$ residues equivalent to the generation of the $\mathrm{CdO}$ (calcd: $31.27 \%$ ).

\section{Photoluminescent properties of compounds 1-2}

The metal-organic frameworks (MOFs) on the basis of the transition metal ions of $\mathrm{d}^{10}$ are the present study hotspot because of their applications in the chemical sensors, electroluminescent displays, along with the photochemistry $[24,25]$. Herein, the two compounds' (using the crystalline samples which were dried in the air for one day) associated organic ligands and luminescent performances were explored in the solid under environmental temperature (Fig. 3). It was observed that the free ligand of $4-\mathrm{H}_{4} \mathrm{Cptpy}$ reflects the emission band with the maximum peak $386 \mathrm{~nm}$ upon $320 \mathrm{~nm}$ excitation, and at $319 \mathrm{~nm}$, the ligand of $\mathrm{H}_{3}$ btc displays the emission peak with $290 \mathrm{~nm}$ excitation. For the free organic ligands, the emissions may be because the transitions of $\pi^{\star} \rightarrow n$ and/or $\pi^{\star} \rightarrow \pi$ in the ligand. When excited at $320 \mathrm{~nm}$, the 1 possesses a strong emission band centered at $388 \mathrm{~nm}$, which should be interpreted as intraligand luminescent emission because of the similar emission for the free 4-Hpctpy ligand [26]. With $360 \mathrm{~nm}$ excitation and at $442 \mathrm{~nm}$, the 2 reveals an intense emission. Obviously, the emission peak of 2 is redshifted via $123 \mathrm{~nm}, 56 \mathrm{~nm}$, respectively, with respect to that of the free $\mathrm{H}_{3}$ btc and 4-Hcptpy ligands. The absence of ligand-based luminescence and significant red-shift emission indicate that the complex 2's luminescence may be derived from charge transfer between the metal centers and organic ligands. Compared to that of the free ligands, the more intense luminescence of 1-2 may be resulted from the 
increased organic ligand conformational rigidity when coordinated with the central metal ions that can effectively decrease the nonradiative decay of intraligand excited states [27].

\section{Compound could significantly reduce the activation levels of the NF-kb signaling pathway after cataract surgery}

After the synthesis of compounds 1 and $\mathbf{2}$, their inhibitory activity on the NF-kb signaling pathway activation levels in cataract endothelial cells after cataract surgery. Thus, the real time RT-PCR was implemented in the work. As the data revealed in the Fig. 5, it can be observed that the model group has a much higher NF-kb signaling pathway activation level in the cataract endothelial cells, in comparison with control group, with $\mathrm{P}<0.005$. After the treatment of compound 1 , the NF-kb signaling pathway activation levels after cataract surgery was remarkably down-regulated, but the $\mathbf{2}$ exhibited only minor effect on the NF-kb signaling pathway activation.

\section{Compound obviously suppressed the content of inflammatory cytokines released after cataract surgery}

In the above research, we have revealed that compound 1 has excellent application values on the NF-kb signaling pathway activation levels in cataract endothelial cells. Furthermore, the content of inflammatory cytokines regulated by the signaling pathway of NF-kb was measured. The results showed in Fig. 6 indicated that in model group, the NF-kb signaling pathway activation levels was much higher, in contrast to control group. In accordance with above data, the 1 was stronger than compound 2 on inhibiting the content of inflammatory cytokines released after cataract surgery.

\section{Compound exhibited no cytotoxicity on the corneal endothelial cells}

Though the above experiments, we have confirmed that compound 1 was much stronger than compound 2 on PIE treatment by reducing the activation levels of the NF-KB signaling pathway and the releasing of the inflammatory cytokines. For the clinical application of the new candidates, the cytotoxicity of compounds 1 and 2 were further evaluated with CCK-8 assay. The data in Fig. 7 suggested, compared with the control group, both compounds 1 and $\mathbf{2}$ showed no inhibitory activity on the viability of corneal endothelial cells. In addition to this, the metal ions and ligands all showed no cytotoxicity on the viability of corneal endothelial cells.

\section{Conclusions}

In conclusion, two fresh coordination polymers, with the chemical formula of $\left[\mathrm{Cd}_{3}(\mathrm{btc})_{2}(4-\mathrm{cptpyH})(\mathrm{DMF})\right.$ $\left.\left(\mathrm{H}_{2} \mathrm{O}\right)_{3}\right]_{n}$ and $\left[\mathrm{Zn}(4-\mathrm{cptpy})(\mathrm{HCOO})\left(\mathrm{H}_{2} \mathrm{O}\right)\right]_{n} \cdot n(\mathrm{DMF})(1)$ have been produced in success with the conditions of solvothermal. The 1 is the 2 -fold interpenetrated two-dimensional layer having three-linked topology of 
hcb, and the H-bonds in the molecular in-depth linked these two-dimensional layers into the threedimensional supramolecular skeleton. While the 2 is a complicated three-dimensional skeleton and it can be classified into a $(3,6)$-linked network of topology on the basis of 4 distinct nodes. Furthermore, the two compounds reflect luminescence at room temperature, exhibiting that they can be applied as excellent backup materials for the photoactive materials. The real time RT-PCR data revealed that the 1 was more superior than the 2 on reducing the activation of NF-kb signaling pathway. Besides, the 1 could also evidently suppress the inflammatory cytokines releasing after cataract surgery, but not compound 2 . Most importantly, both compounds 1 and $\mathbf{2}$ showed no toxicity on the corneal endothelial cells. In the end, we draw this conclusion, compound $\mathbf{1}$ was much more outstanding than compound $\mathbf{2}$ on PIE treatment through inhibiting the inflammatory response.

\section{Declarations}

\section{Conflicts of Interest}

The author(s) declare(s) that there is no conflict of interest regarding the publication of this paper.

\section{Data Availability}

Selected bond lengths $(\AA)$ and angles $\left(^{\circ}\right)$ for compound 1 (Table S1), the hydrogen bonding parameters for compound $\mathbf{1}$ (Table S2), the coordination modes of the organic ligands (a) for compound $\mathbf{1}$ (b) and (c) for compound 2 (Fig. S1), the 2-fold interpenetrated hcb network for 1 (Fig. S2), the dinuclear $\left[\mathrm{Cd}_{2}(\mathrm{COO})_{2}\right]$ subunit in compound $\mathbf{2}$ (Fig. S3), the PXRD patterns (a) for compound $\mathbf{1}$ and (b) for compound $\mathbf{2}$ (Fig. S4), the information could be found in the supporting information file.

\section{Acknowledgments}

Not applicable.

\section{References}

1. Rahmani S, Eliott D. Postoperative Endophthalmitis: A Review of Risk Factors, Prophylaxis, Incidence, Microbiology, Treatment, and Outcomes. Semin Ophthalmol. 2018; 33: 95-101.

2. Clarke B, Williamson TH, Gini G, Gupta B. Management of bacterial postoperative endophthalmitis and the role of vitrectomy. Surv Ophthalmol. 2018; 63: 677-693.

3. H. J. Chen, P. Fan, X. X. Tu, H. Min, X. Y. Yu, X. F. Li, J. L. Zeng, S. W. Zhang, P. Cheng, A bifunctional luminescent metal-organic framework for the sensing of paraquat and Fe3+ ions in water, Chem.-An Asian J., 2019, 14, 3611-3619.

4. Y. E. Cheon, M. P. Suh, Selctive gas adsorption in a microporous metal-organic framework constructed of $\mathrm{Co}(\mathrm{II})_{4}$ clusters. Chem. Commun., 2009, 17, 2296-2298. 
5. J. P. Zhang, Y. B. Zhang, J. B. Lin, X. M. Chen, Metal azolate frameworks: from crystal engineering to functional materials. Chem. Rev., 2012, 112, 1001-1033.

6. X. Zhang, Y. Y. Huang, Q. P. Lin, J. Zhang, Y. G. Yao, Using alkaline-earth metal ions to tune structural variations of 1,3,5-benzenetricarboxylate coordination polymers. Dalton Trans., 2013, 42, 2294-2301.

7. M. Du, C. P. Li, C. S. Liu, S. M. Fang, Design and construction of coordination polymers with mixedligand synthetic strategy. Coord. Chem. Rev., 2013, 257, 1282-1305.

8. Y. Y. Qin, J. Zhang, Z. J. Li, L. Zhang, X. Y. Cao, Y. G. Yao, Organically templated metal-organic framework with 2-fold interpenetrated $\left\{3^{3} \cdot 5^{9} \cdot 6^{3}\right\}$-lcy net. Chem. Commun., 2008, 22, 2532-2534.

9. Y. Q. Chen, S. J. Liu, Y. W. Li, G. R. Li, K. H. He, Z. Chang, X. H. Bu, Mn(II) metal-organic frameworks based on Mn3 clusters: from 2D layer to 3D framework by the "pillaring" approach. CrystEngComm, 2013, 15, 1613-1617.

10. C. W. Lv, J. Li, Z, Hou, M. K. Li, Synthesis, structure and luminescent property of a new Zn(II) coordination polymer with isolated tetrahedral $\left\{\mathrm{Zn}_{4} \mathrm{O}\right\}$ clusters as building subunits. Inorg. Chem. Commun., 2013, 36, 1-3.

11. Q. X. Liu, L. B. Ni, F. P. Liang, Z. H. Zhou, H. L. Wan, pH and molar ratio dependent formation of monomeric, dimeric and tetrameric cobalt malate complexes. Polyhedron, 2009, 28, 917-922.

12. X. Y. Cao, J. Zhang, Z. J. Li, J. K. Cheng, Y. G. Yao, Scorpion-shaped carboxylate ligand tailored molecular square, bilayer, self-threading and (3,6)-connected nets. CrystEngComm, 2007, 9, 806-814.

13. X. Zhang, Y. Y. Huang, Y. G. Yao, Two distinct Dy-isophthalates induced by different solvents. J. Mol. Struct., 2012, 1024, 146-150.

14. Y. T. Wang, H. H. Fan, H. Z. Wang, X. M. Chen, A solvothermally in situ generated mixed-ligand approach for NLO-active metal-organic framework materials. Inorg. Chem., 2005, 44, 4148-4150.

15. G. L. Wen, G. P. Yang, P. Liu, B. Liu, Y. Y. Wang, Temperature-controlled spontaneous resolution of enantiomerically threefold interpenetrating arm-shaped MOFs with achiral symmetrical ligands. Inorg. Chem. Commun., 2018, 94, 104-107.

16. J. Yang, X. Wang, R. Wang, L. Zhang, F. Liu, F. Dai, D. Sun, Syntheses, crystal structures, and properties of two 2-fold interpenetrating metal-organic frameworks based on a trigonal rigid ligand. Cryst. Growth \& Des., 2014, 14, 6521-6527.

17. L. Wen, X. Ke, L. Qiu, Y. Zou, L. Zhou, J. Zhao, D. F. Li, Assembly of two porous cadmium(II) frameworks: selective adsorption and luminescent property. Cryst. Growth \& Des., 2012, 12, 40834089.

18. B. Li, Q. Q. Yan, G. P. Yong, Crystal structures and properties of four coordination polymers based on a new asymmetric ligand: Tuning structure/dimensionality by various organic solvents. Inorg. Chim. Acta, 2020, 503, 119403.

19. H. Y. Liu, G. M. Gao, J. Liu, H. Y. Wang, Two metal-organic frameworks based on carboxyphenylterpyridine ligands: Synthesis, structure and highly luminescent sensing of nitrobenzene. Polyhedron, $2018,152,11-16$. 
20. S. X. Xiong, J. J. Zhang, R. Wang, B. H. Wu, J. Chen, X. Q. Wang, R. L. Zhang, M. Gong, Z. Li, M. N. Qu, Enhancing the electrochromic properties of polyaniline through incorporating terpyridine units and coordination bonding with transition metal ions. Chemistryselect, 2019, 4, 14343-14350.

21. G. M. Sheldrick, Acta Crystallogr., Sect. C: Struct. Chem., 2015, 71, 3-8.

22. V.A. Blatov, A.P. Shevchenko, D.M. Proserpio, Applied Topological Analysis of Crystal Structures with the Program Package ToposPro, Cryst. Growth Des. 14 (2014) 3576-3586. doi:10.1021/cg500498k.

23. H. Cai, N. Li, Y. Li, D. M. An, New three-dimensional Zn(II)/Cd(II)-based coordination polymers as luminescent sensor for $\mathrm{Cu}^{2+}$. Inorg. Chim. Acta, 2020, 512, 119886.

24. J. J. Zhao, L. Zhang, P. Y. Liu, W. Z. Chen, Z. L. Liu, Y. Q. Wang, Water-stable Cd(ii)/Zn(ii) coordination polymers as recyclable luminescent sensors for detecting hippuric acid in simulated urine for indexing toluene exposure with high selectivity, sensitivity and fast response. Dalton Trans., 2021, 50, 553-561.

25. Y. P. Qu, L. L. Gao, Y. J. Zhang, TWO 3D Cd (II) luminescent coordination polymers as highly selective and sensitive sensing for $\mathrm{Fe}^{3+}$ and $\mathrm{CrO}_{4}{ }^{2-} / \mathrm{Cr}_{2} \mathrm{O}_{7}{ }^{2-}$ ions in aqueous system. J. Solid State Chem., 2020, 292, 121637.

26. Q. Zhu, T. Sheng, R. Fu, C. Tan, S. Hu, X. Wu, Two luminescent enantiomorphic 3D metal-organic frameworks with 3D homochiral double helices. Chem. Commun., 2010, 46, 9001-9003.

27. H. Yersin, A. E. Vogler, Photochemistry and photophysics of coordination compounds; SpringerVerlag: Berlin, 1987.

\section{Figures}


(a)

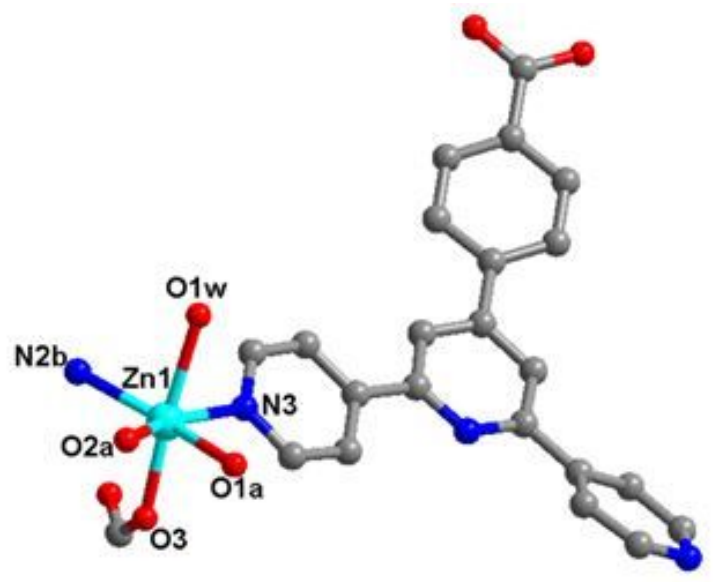

(c)

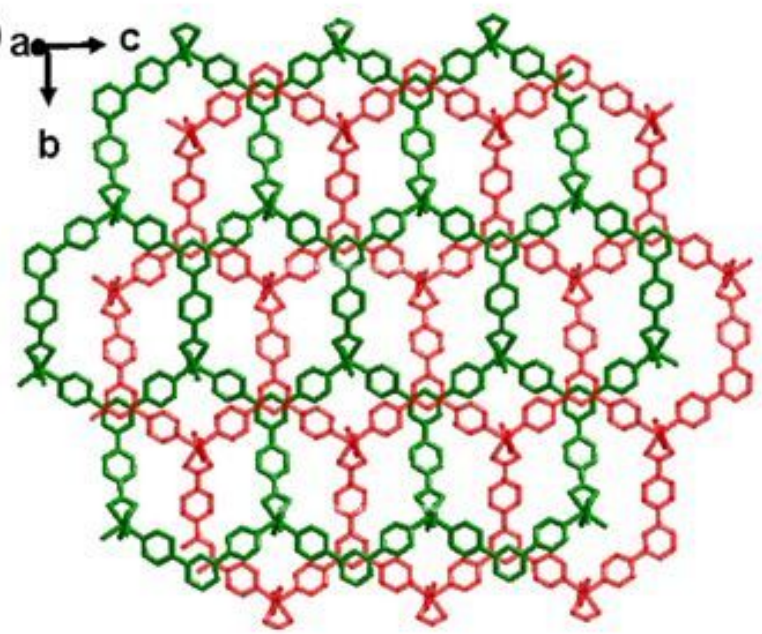

(b)

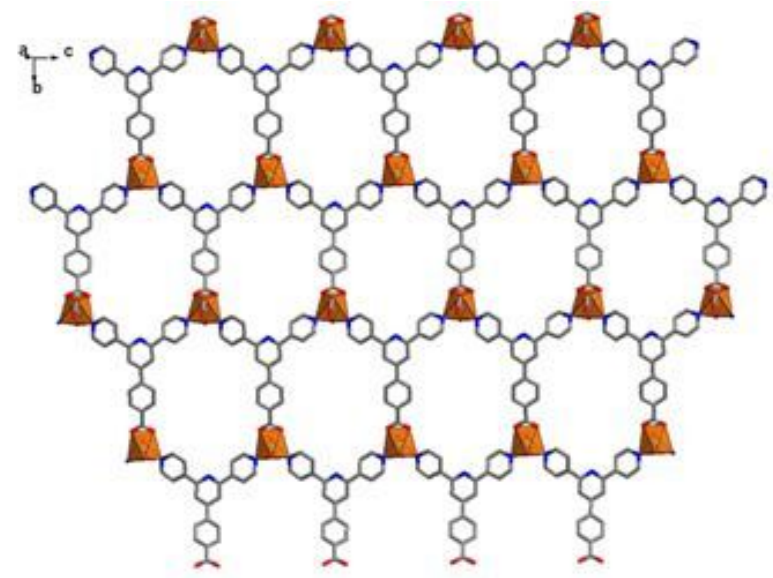

(d)

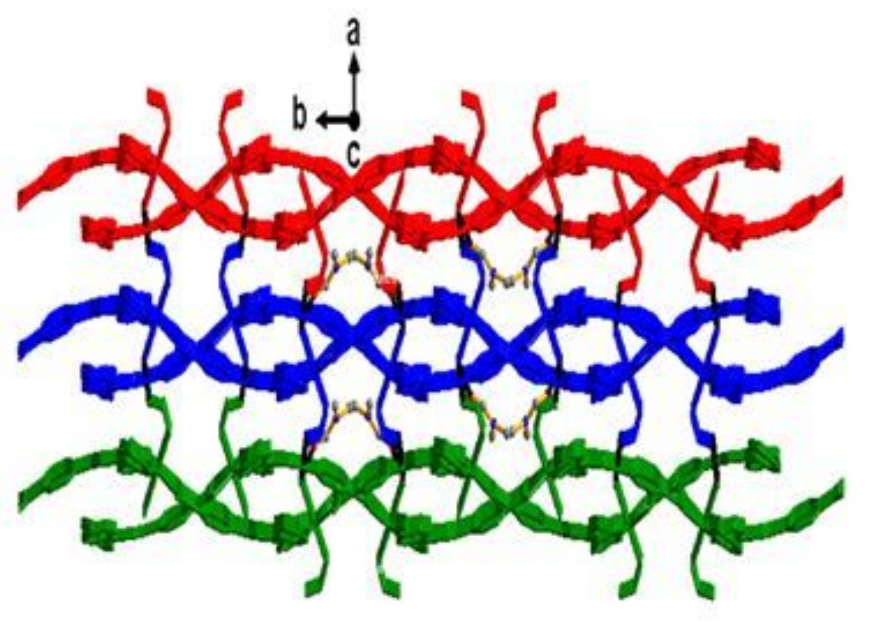

Figure 1

(a) The coordination surrounding view of the $\mathrm{Zn}(\mathrm{II})$ ion in complex 1. (b)The two-dimensional layer single architecture. (c) The 2-fold interpenetrated two-dimensional layer (d) The three-dimensional supramolecular skeleton established through hydrogen bonds between the molecular (black dotted lines represents the hydrogen bond). 

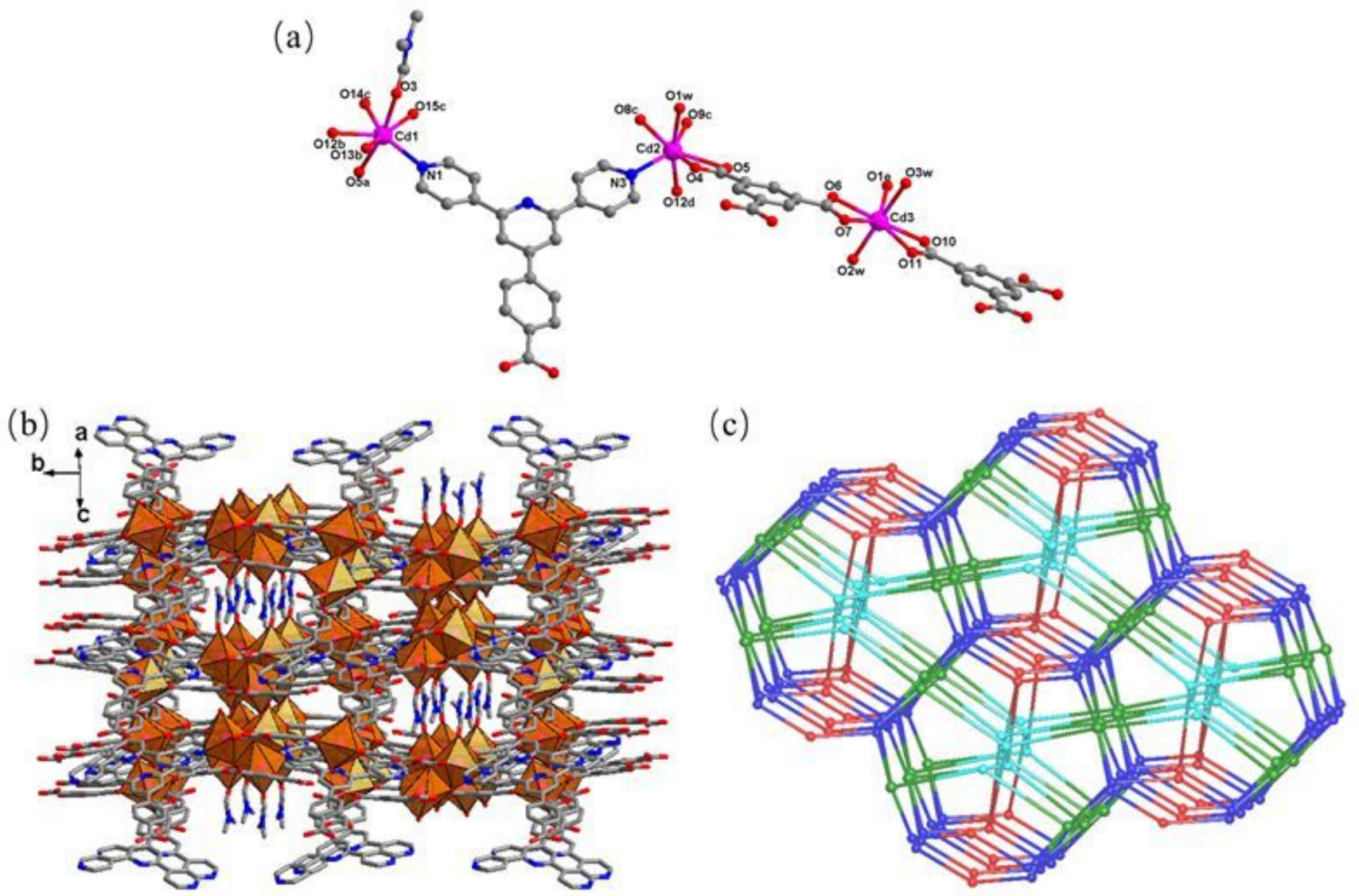

Figure 2

(a) The coordination surrounding view of the Cd(II) ions in compound 2. (b) The 2's three-dimensional complicated skeleton. (c) The 2's schematic representation of $(3,6)$-linked net of topology.

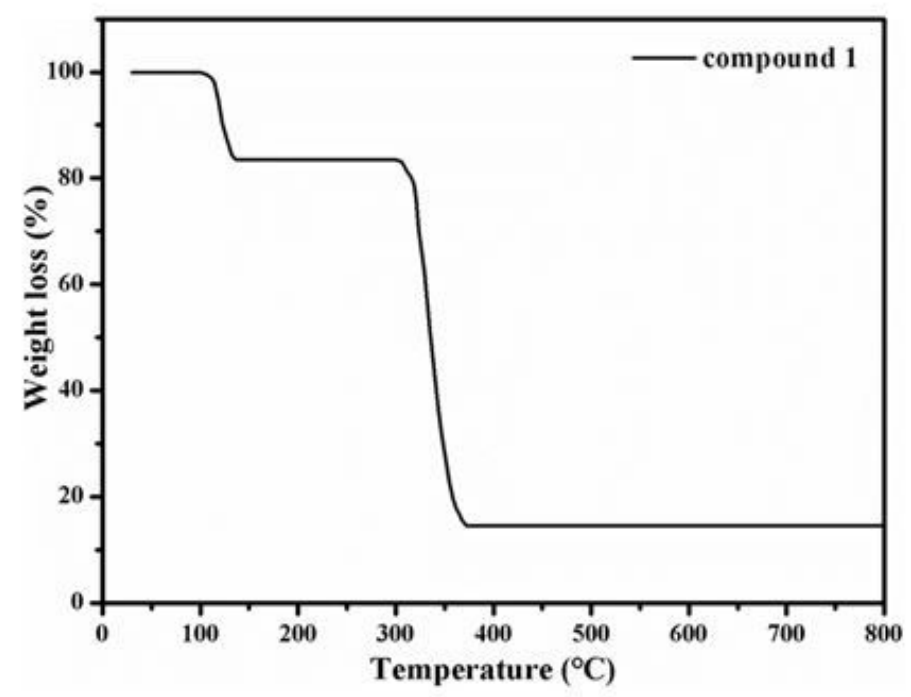

(a)

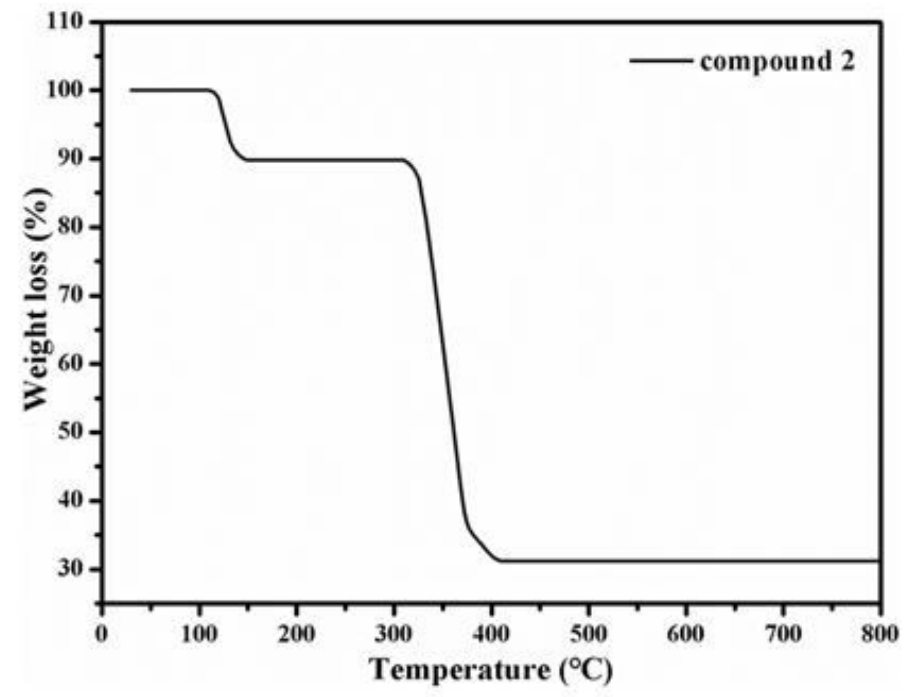

(b)

Figure 3 
The curves of TGA (a) for the 1 and (b) for the 2 .
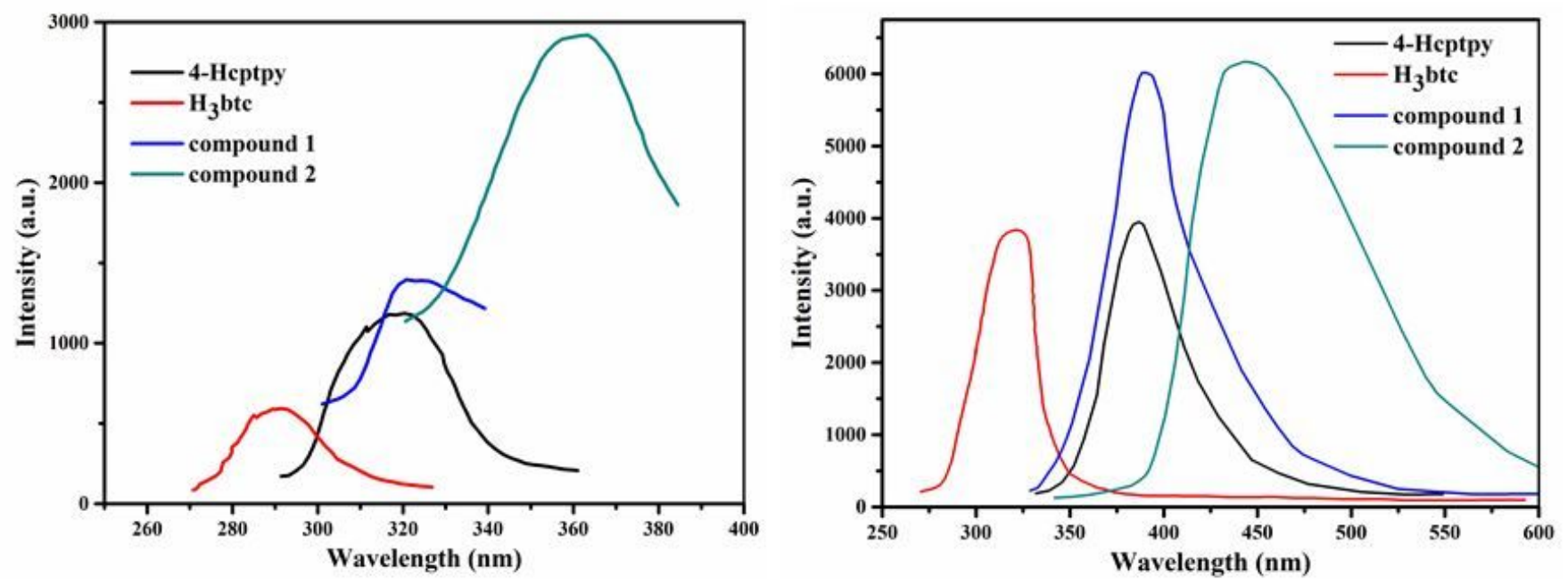

Figure 4

The luminescent excitation (left) and emission spectrum (right) for the free H3btc and 4-Hcptpy ligands and the two compounds at room temperature.
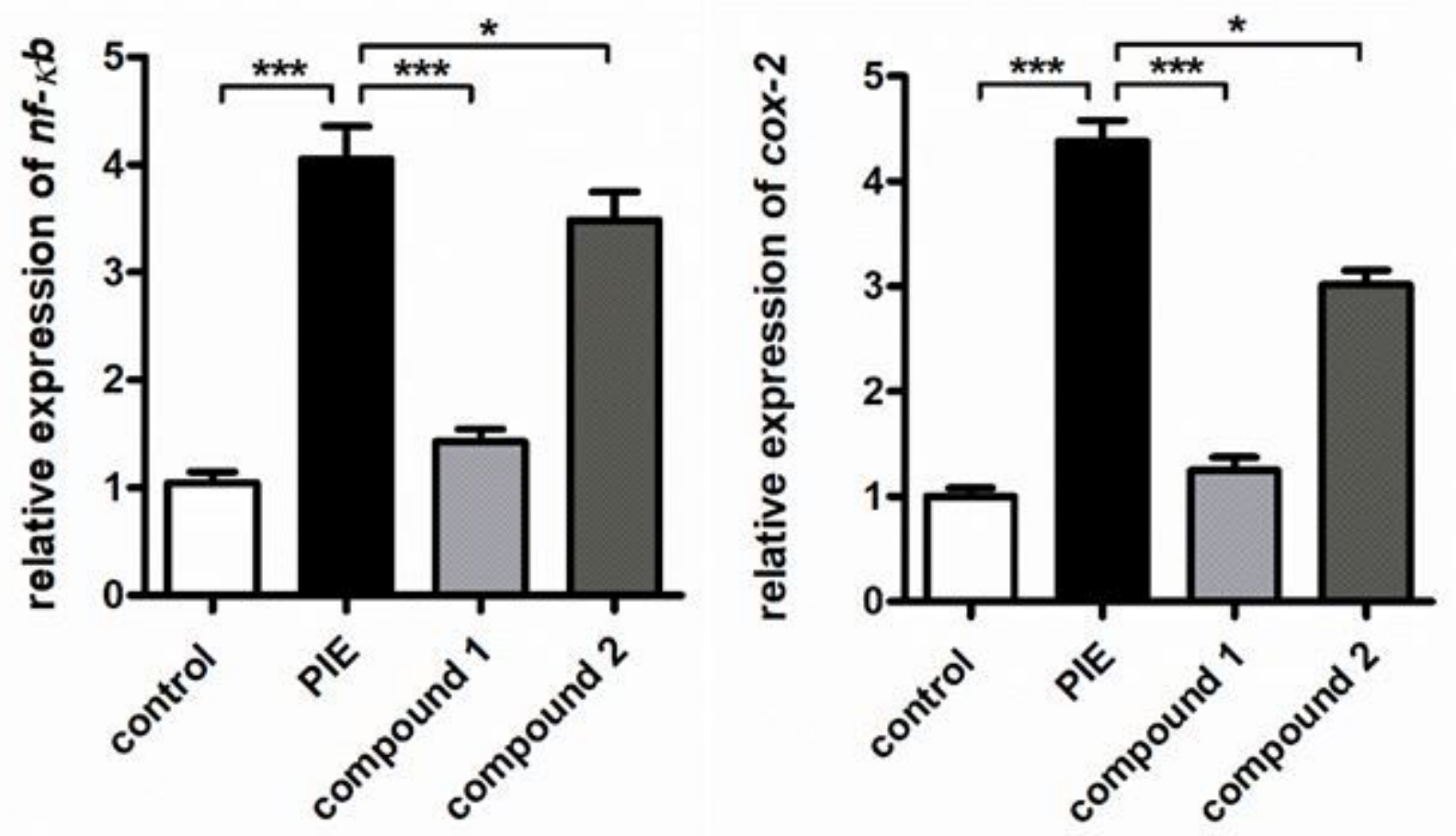

\section{Figure 5}

Significantly reduced NF-kb signaling pathway activation levels after cataract surgery. The cataract surgery was conducted and the Staphylococcus epidermidis was used to induce the postoperative infection, compounds were given for indicated treatment $(5 \mathrm{mg} / \mathrm{kg})$. The real time RT-PCR was completed 
and the NF-kb signaling pathway activation levels in cataract endothelial cells was determined. * means $\mathrm{P}<0.05$, *** means $\mathrm{P}<0.005$.
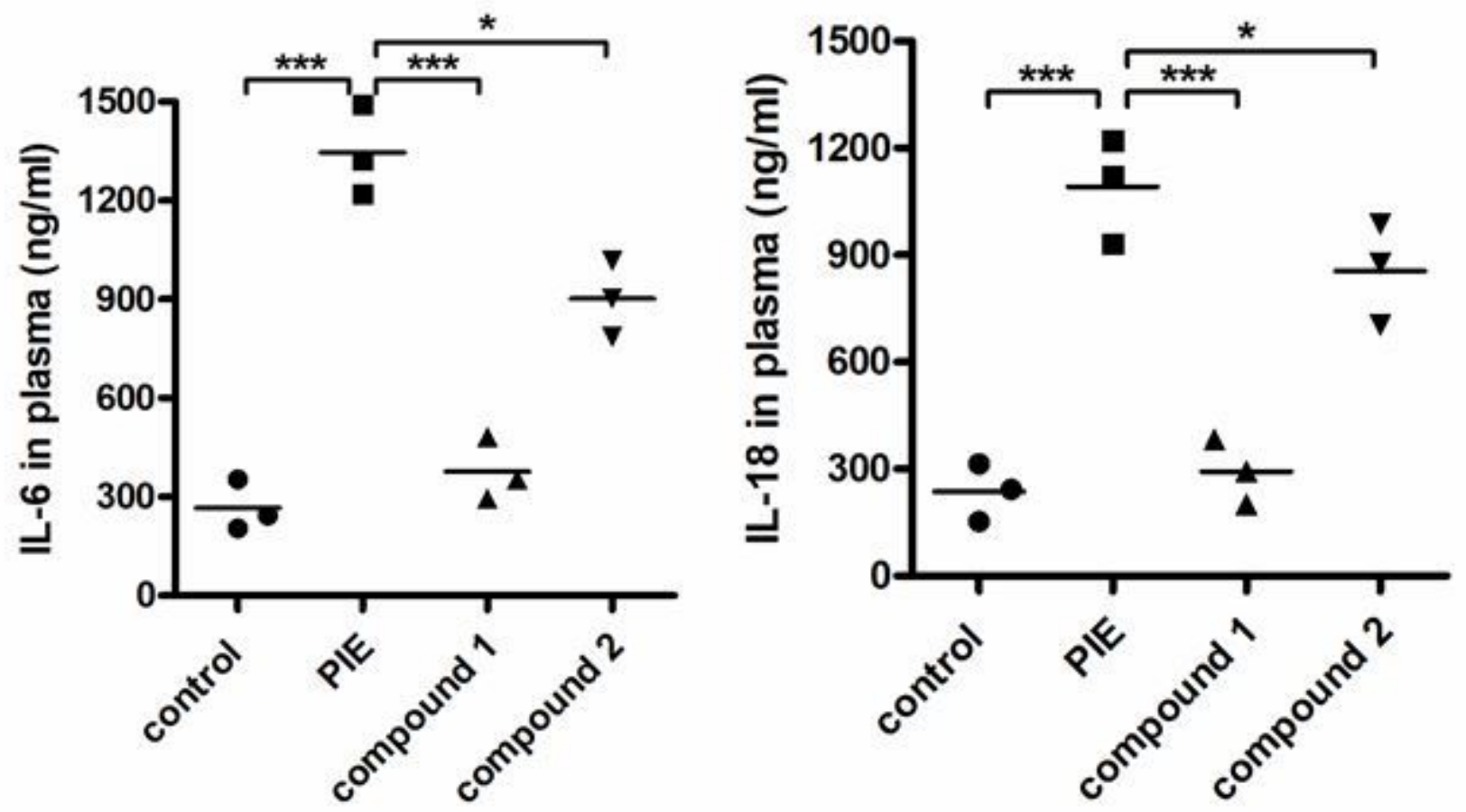

Figure 6

Obviously suppressed content of inflammatory cytokines released after cataract surgery after compound treatment. The cataract surgery was conducted and the Staphylococcus epidermidis was used to induce the postoperative infection, compounds were given for indicated treatment $(5 \mathrm{mg} / \mathrm{kg})$. The plasma was collected and the inflammatory cytokines content released after accomplishing the cataract surgery was measured through exploiting the ELISA detection kit. * means $P<0.05$, *** means $P<0.005$.

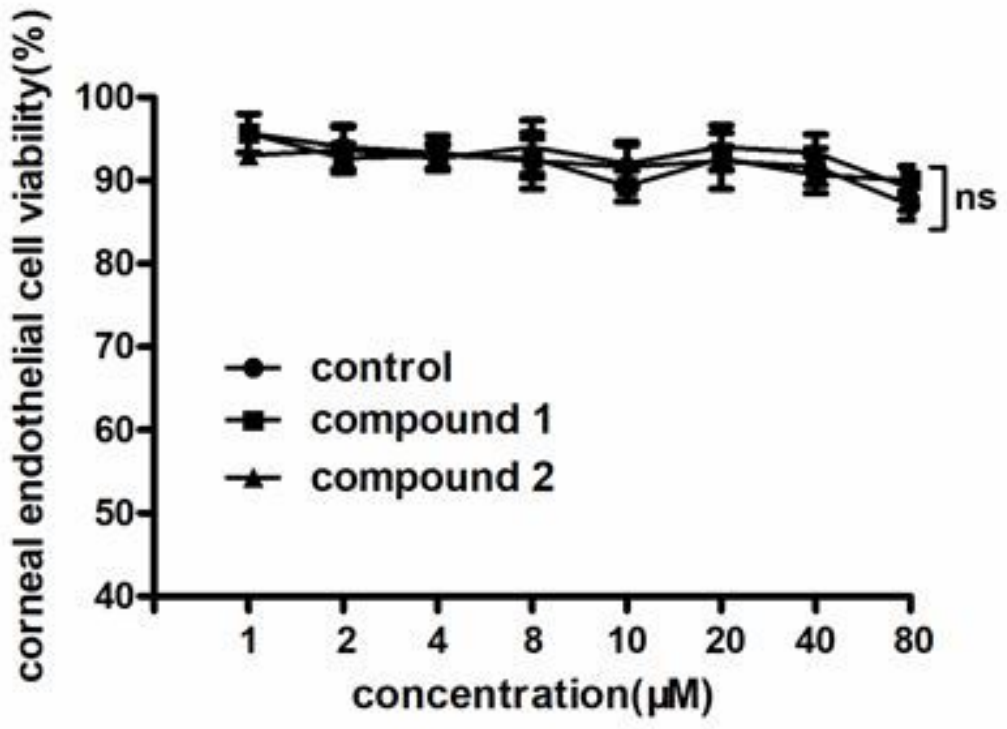




\section{Figure 7}

No cytotoxicity of the compounds on the viability of corneal endothelial cells. The corneal endothelial cells in logical growth phage were added with the two compounds can be added for treatment with different concentration. The viability ability of corneal endothelial cells was detected with the CCK-8 assay.

\section{Supplementary Files}

This is a list of supplementary files associated with this preprint. Click to download.

- SupplementaryMaterial.doc 